Fac. Vet. Med., Al-Baath Univ., Syria

\title{
ISOLATION AND CLASSIFICATION OF ASPERGILLUS FUNGI AT CHICKS OF BROILER BREEDER IN SYRIA
}

\author{
(With One Table and 5 Figures)
}

By

\section{FOUAD AL-DAOUAD; A.H. MOKRESH and I.RAFIA}

(Received at 27/10/2010)

$$
\begin{aligned}
& \text { عزل وتصنيف فُطْريَّات الرَّشََّّثِيِّات عند صيصان دجاج اللحم في سوريا }
\end{aligned}
$$

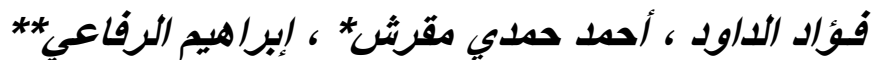

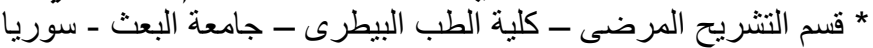

$$
\begin{aligned}
& \text { ** قسم الأحياء الدقيقة - كلبة الطب البيطرى ـ جامعة البعث - سوريا - سوريا }
\end{aligned}
$$

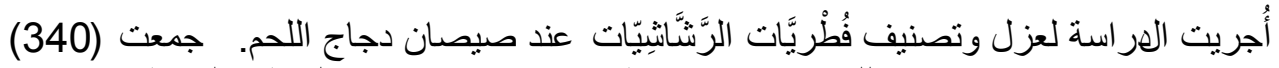

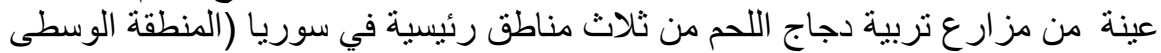

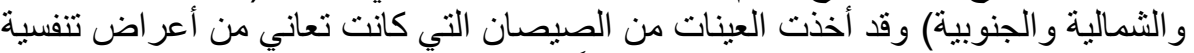

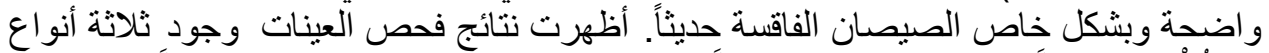

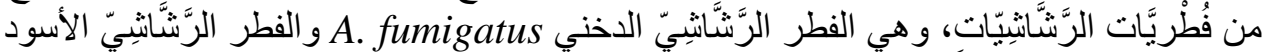

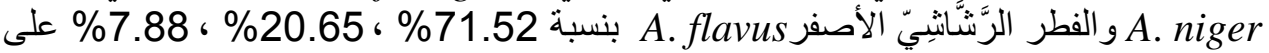
التتابع من إجمالي عدد العينات الإيجابية في جميع مناطق الأدراسة.

\section{SUMMARY}

This study was performed to identify and classification of Aspergillus fungi at the chicks of broiler breeder. 340 Sample were collected from several farms of broiler from three main area of Syria (Middle, Northern, southern). The samples were taken from chicks which revealed respiratory sings. Results showed that there were three kinds of Aspergillus fungi, they A. fumigatus, A. Niger and A. flavus and their percentages were $71.52 \%$, $20.61 \%$ and $7.88 \%$ respectively from the total samples in all Areas studied. This study was performed to identify and classification of Aspergillus fungi at the chicks of broiler breeder. 340 Sample were collected from several farms of broiler from three main area of Syria (Middle, Northern, southern). The samples were taken from chicks which revealed respiratory sings. Results showed that there were three kinds of Aspergillus fungi, they A. fumigatus, A. Niger and A. flavus and their percentages were $71.52 \%$, $20.61 \%$ and $7.88 \%$ respectively from the total samples in all Areas studied.

Key words: Aspergilli, A. flavus, A. niger, A. fumigatus, broilers. 


\section{INTRODUCTION مُعََِِمَة}

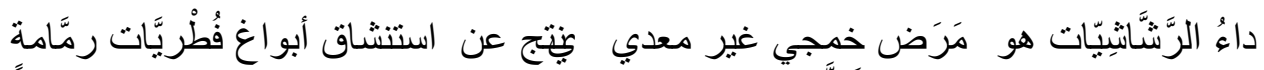

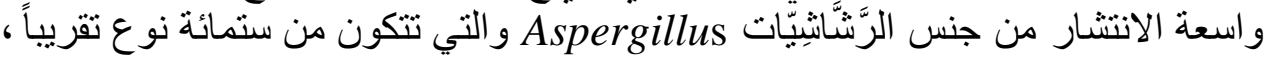

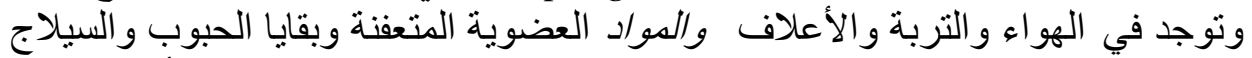

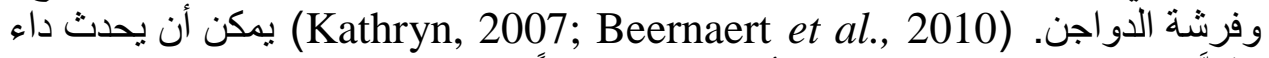

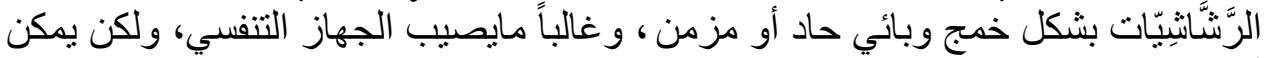

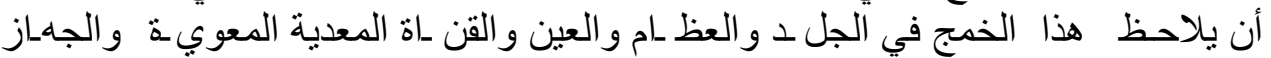

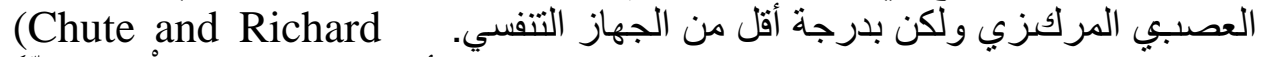

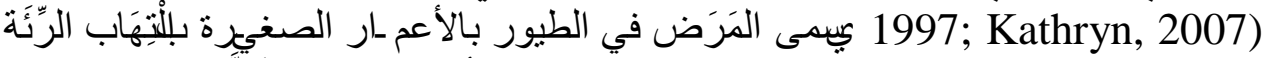

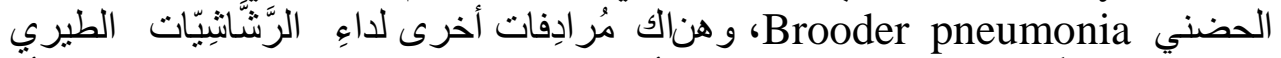

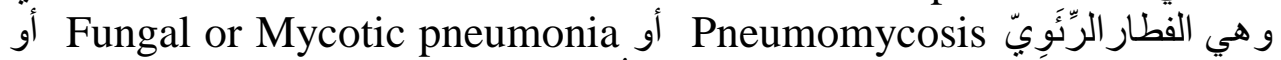

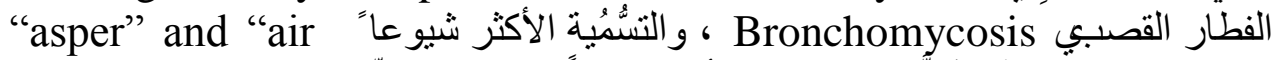

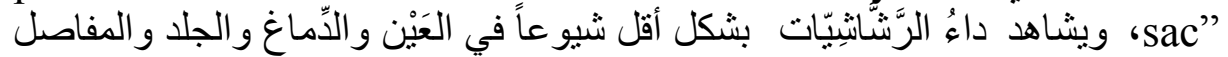

والأحشاء. (Kunkle, 2003)

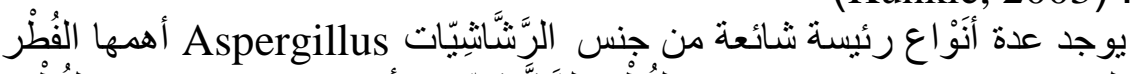

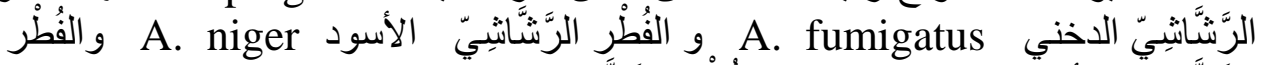

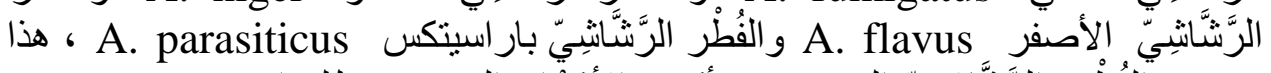

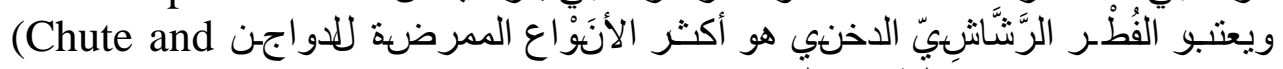

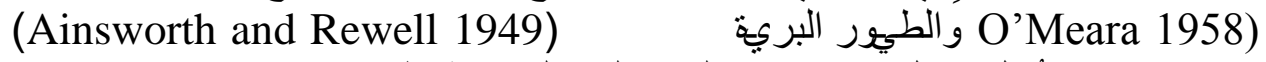
والإنسان حيث عُزل بشكل متكرر من الناس الذين لايهم تثنيط مناعي (Achneemann ( (and Schaffner, 1999 ينم الخمج بداءِ الرَّنَّانثِيَّات بشكل رئيسي عن طريق الاستنشاق، ولكي يحدث

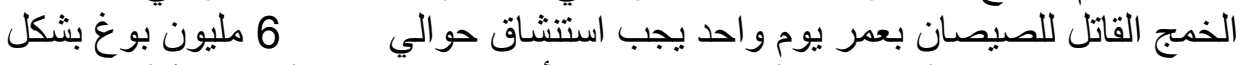

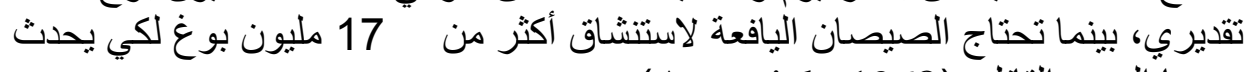
عندها الخمج القاتلك. (Austwick, 1968)

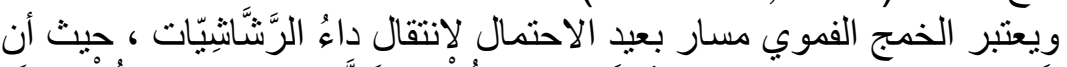

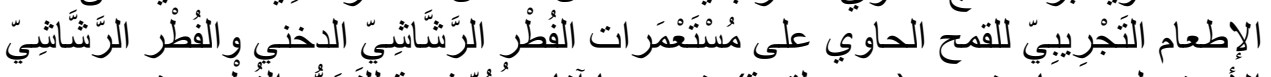

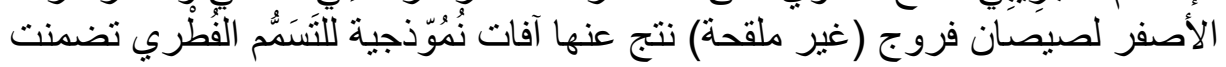

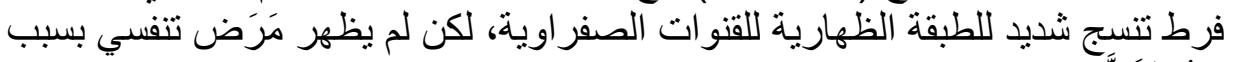

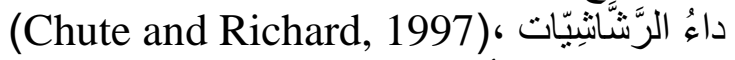

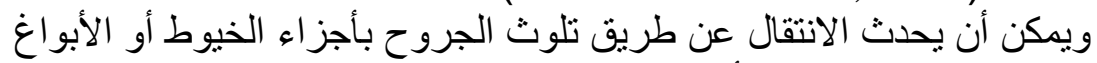
خاصة الجروح التي تفضي إلى الأكياس الهو ائية. (O'Meara and Chute, 1959)

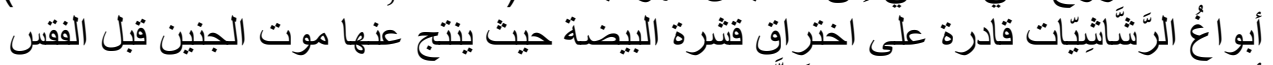

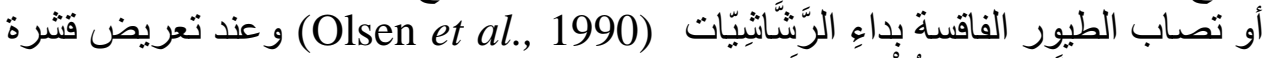

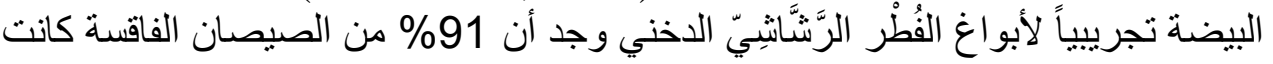




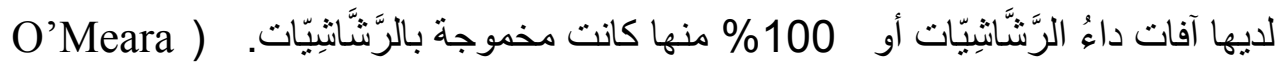
(and Chute, 1959

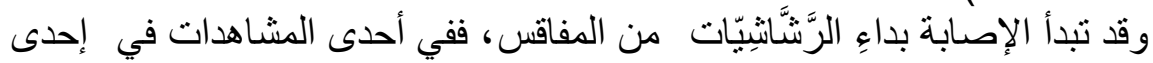

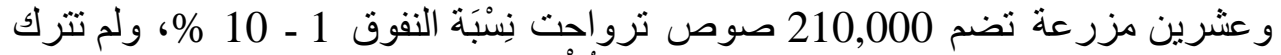

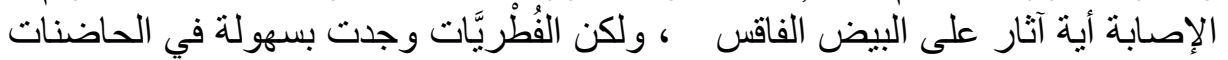

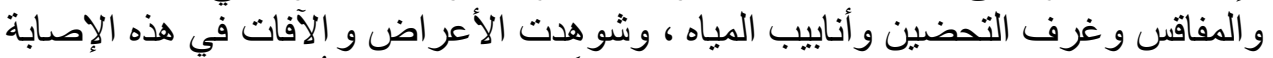

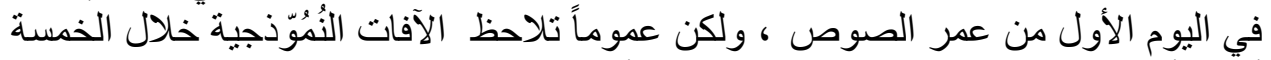

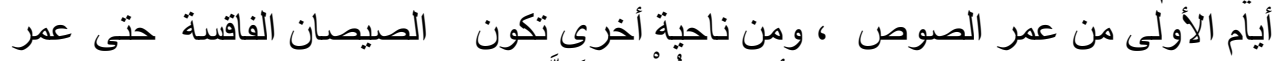

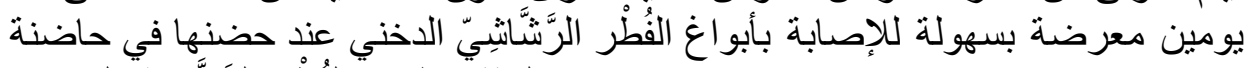

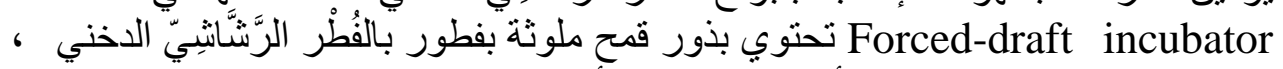

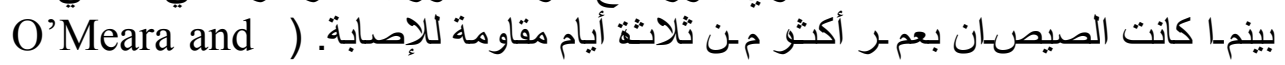
(Chute, 1959

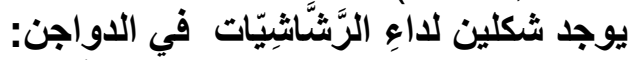

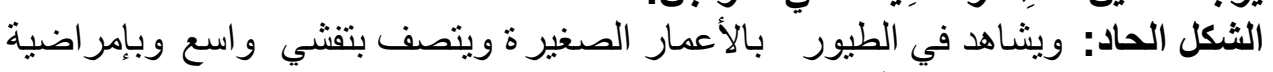

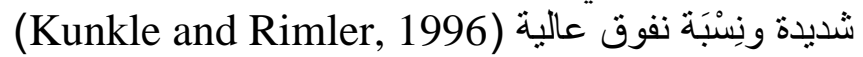

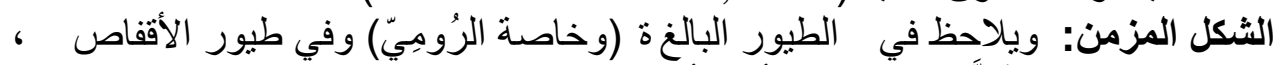

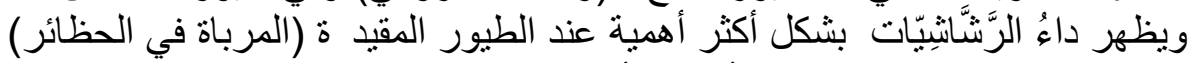

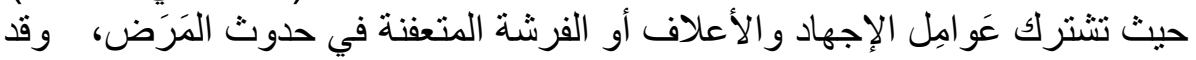

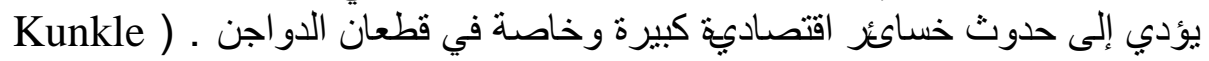
(and Rimler, 1996; Martin et al., 2007

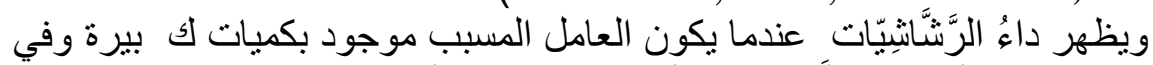

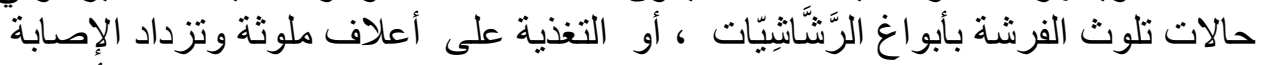

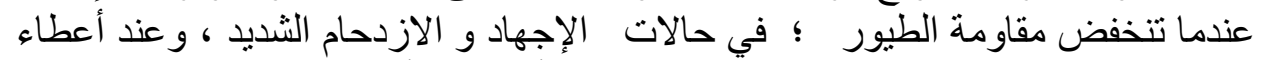
مركبات مثبطة للمناعة، وفي حالات سوء التغذية التية، أو وجود أمر اض معدية. Beckman) et al., 1994)

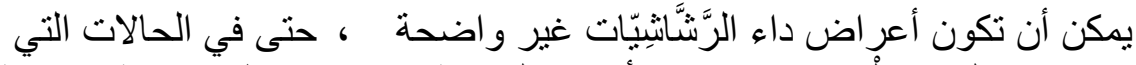

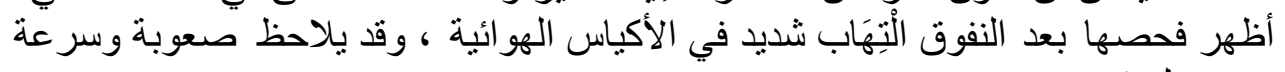
تنفس ولهث. (Akan et al., 2002)

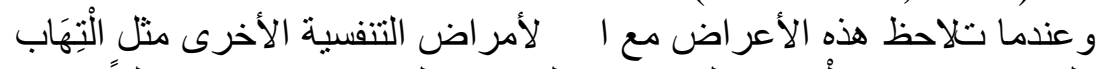

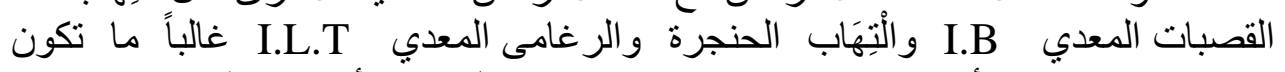

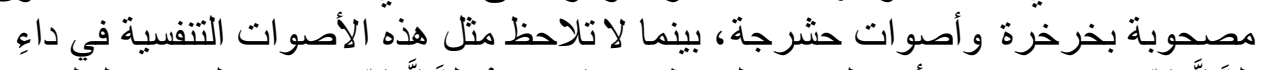

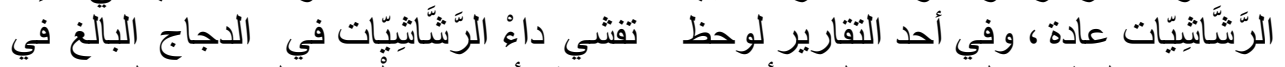

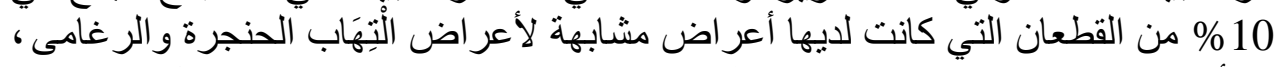

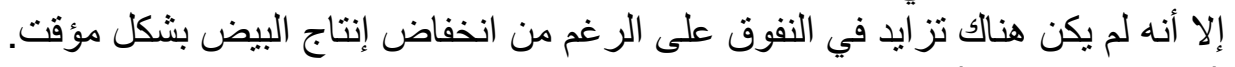

(Kunkle, 2003)

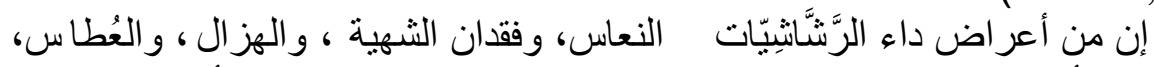

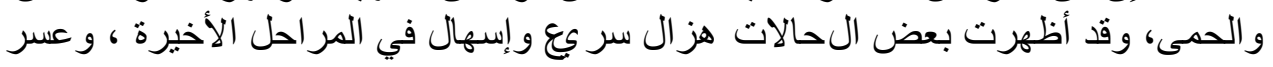




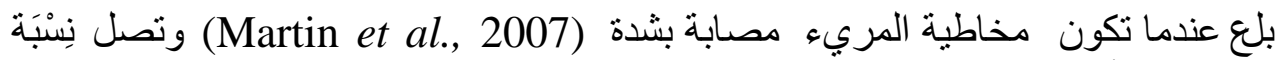

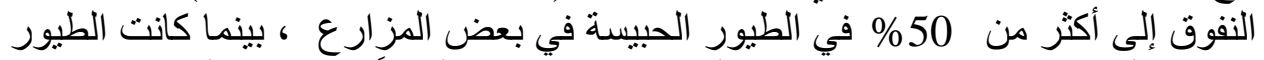

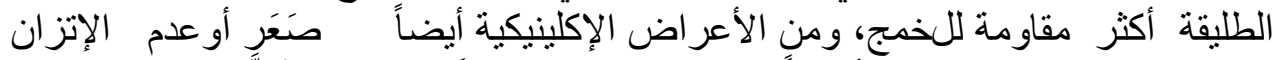

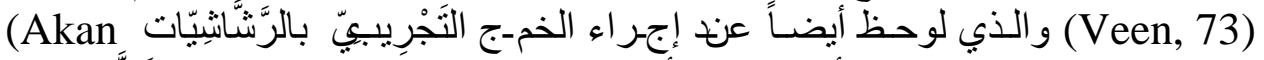

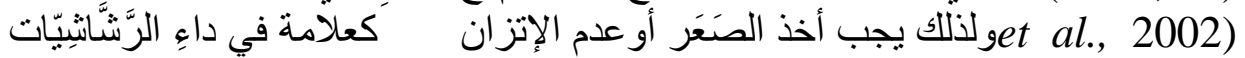

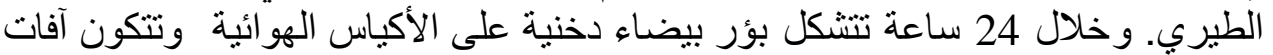

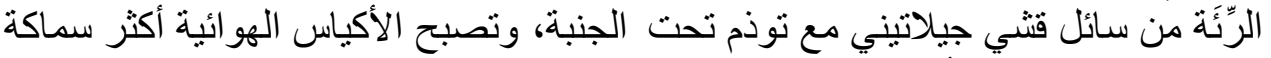

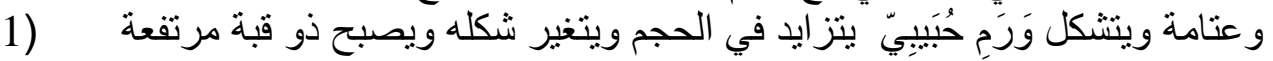
ملم) إلى منبسطة وذات لويحات ذات سرة

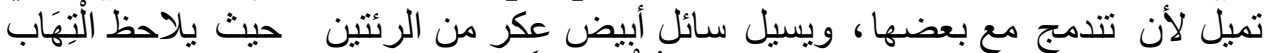

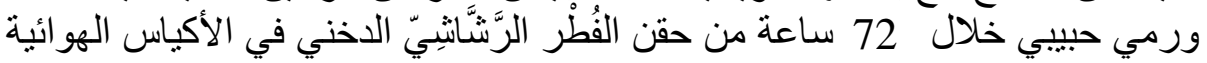
(Kunkle, 2003)

ولعدم وجود در اسات محلية حول داءُ الرَّشَّانِيَّات في سوريا، فقد أجري هذا

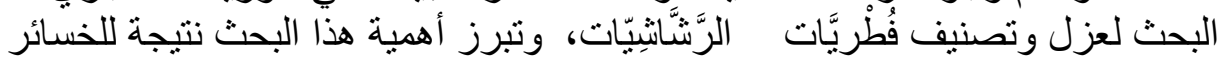

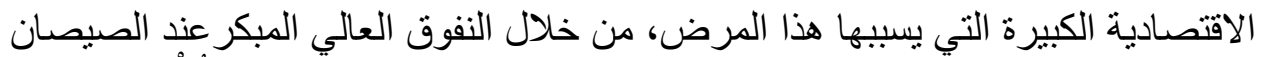

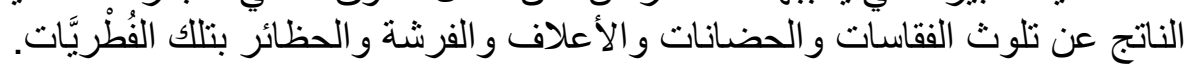

\section{MATERIALS and METHODS المواد وطرق العمل}

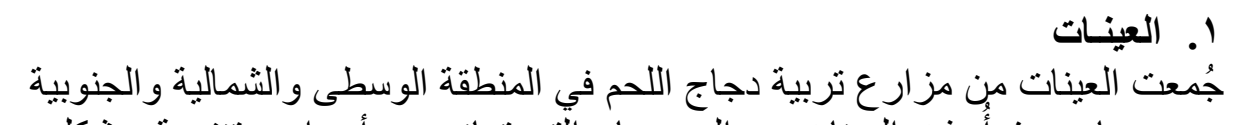

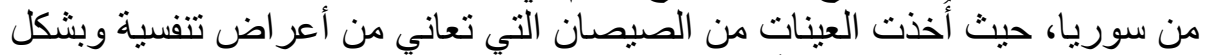

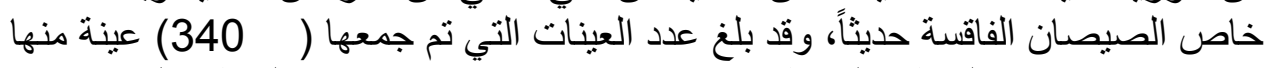

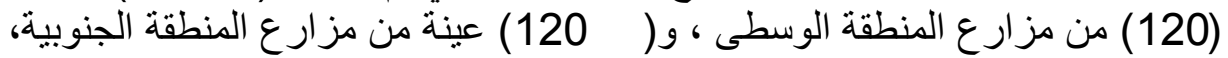

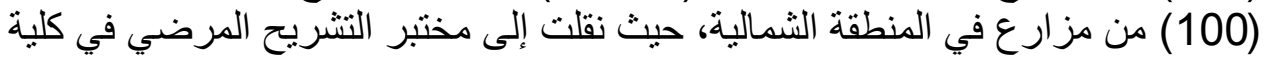

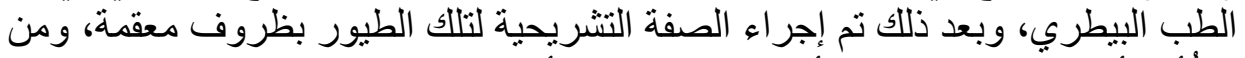

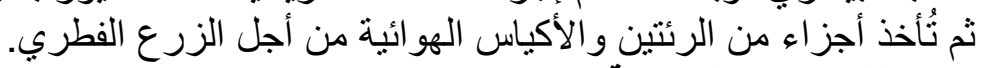

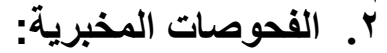

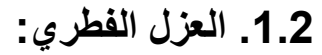

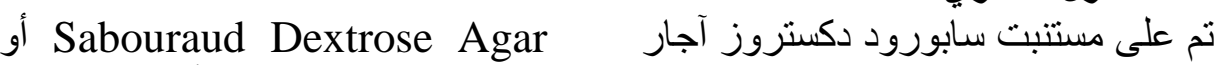
مستنبت آجار دكستروز البطاط I Potato Dextrose Agar حيث يتم أخذ جزء من الركار

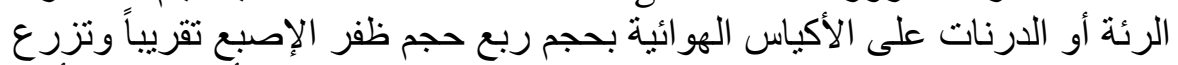

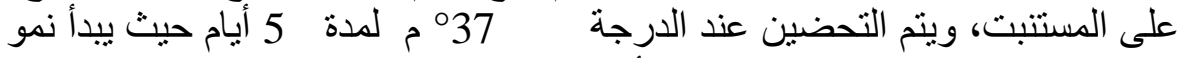
المستعمر المات الفطرية عادة خلال 3-2 أيام.

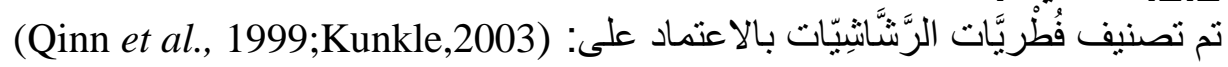




$$
\text { 1.2.2 1.2.2 لون وشكل المستعمر ات الفطرية : 1.2. }
$$

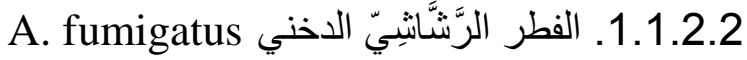

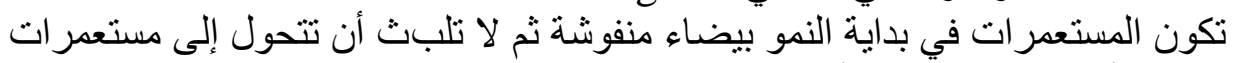

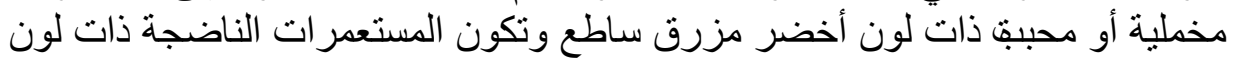

$$
\text { رمادي دخني. }
$$

A. niger 2.1.2.2

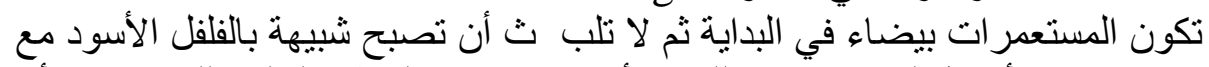

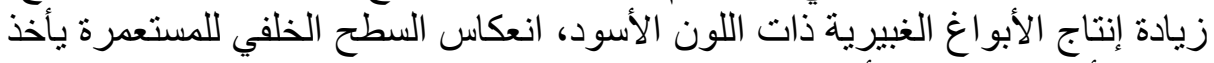
اللون الأصفر البرتقالي أو اللون الكرات الكريمي.

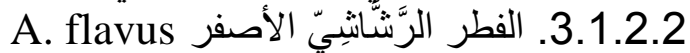
تظهر أفطورات هو ائية قطنية الثكل في بادئ الأمر لا تلبثث أن تصبح خضر اء مصفرة

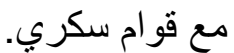

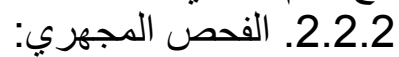

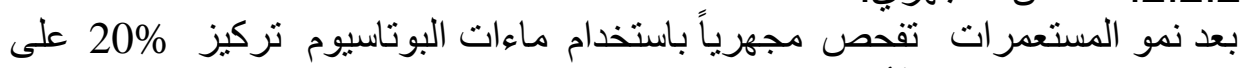

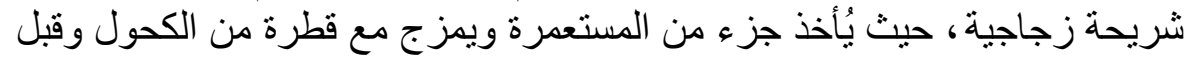

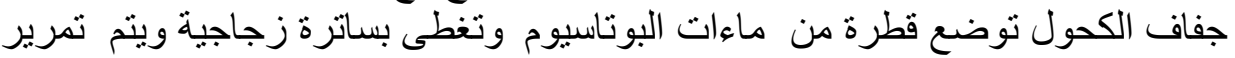

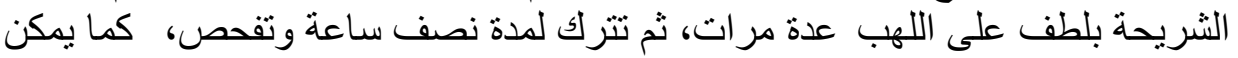

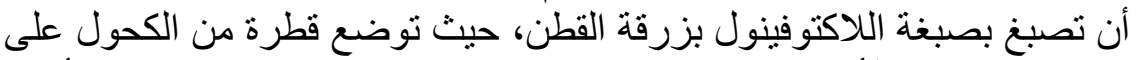

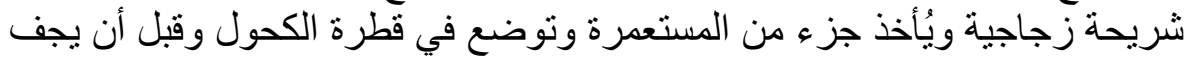

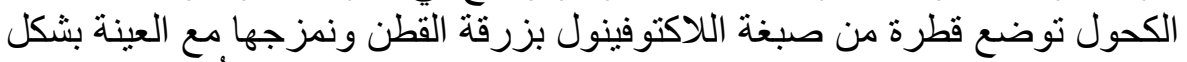

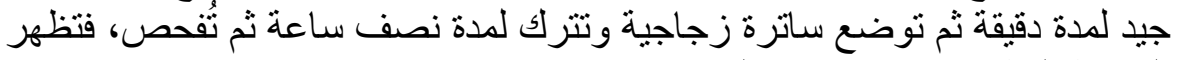

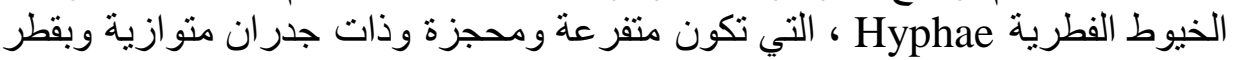

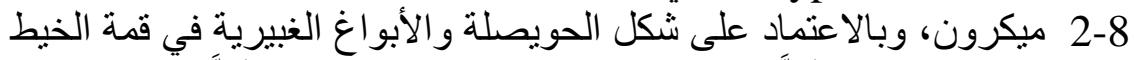

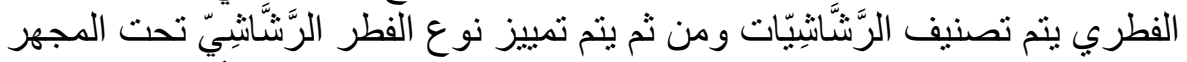

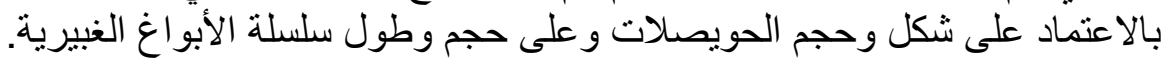

(Qinn et al., 1999; Kunkle, 2003)

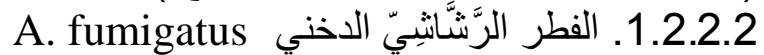

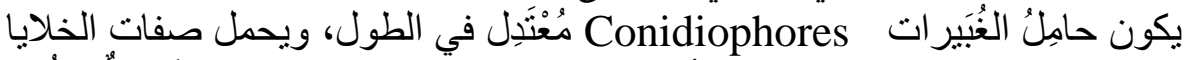

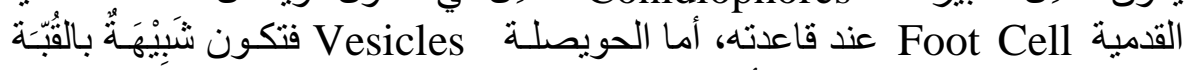
و النصف الأول منها إلى الثلثنين يحمل المجيلات

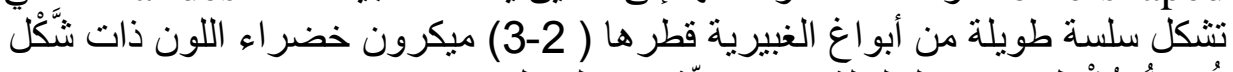

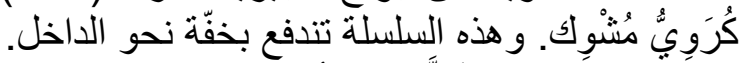

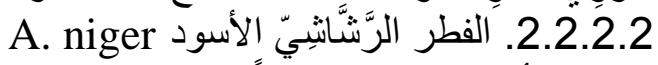

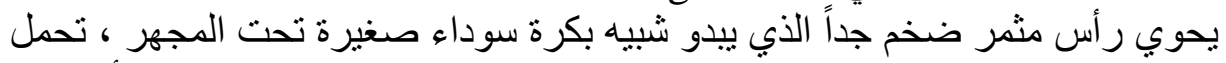

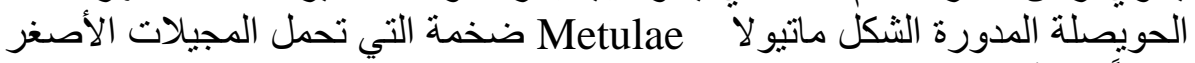

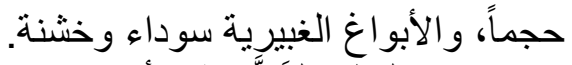

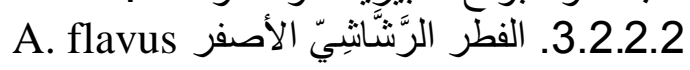




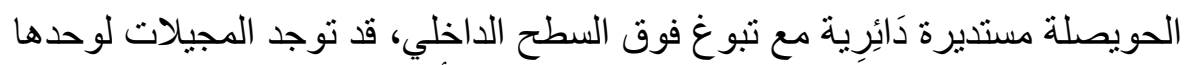

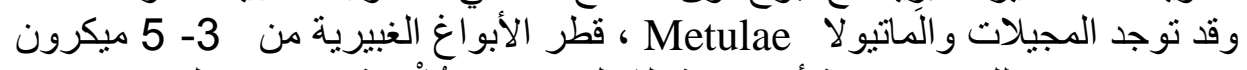

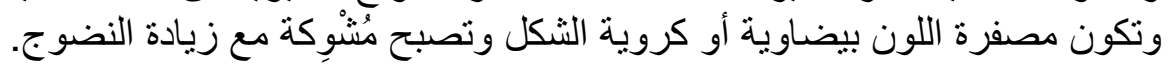

\section{RESULTS}

النتائَج

العلامات الحقلية والآفات التشريحية:

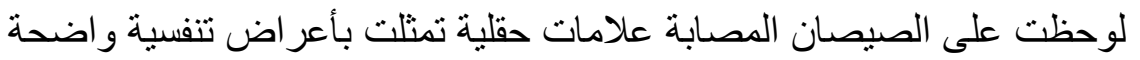

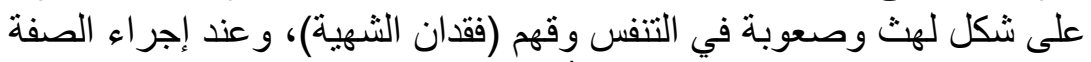

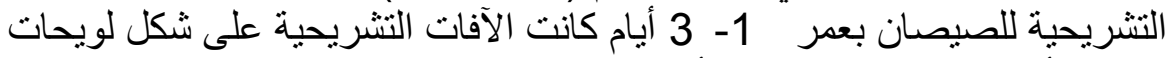

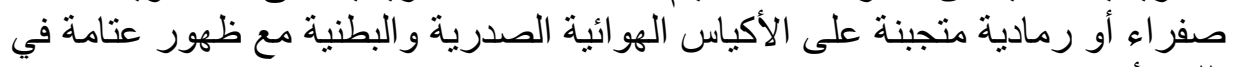
أما في الصيصان بعمر 6 الصائ 6 أيام فما فوق فقد لوحظ وجود درنات فطرية مختلفة

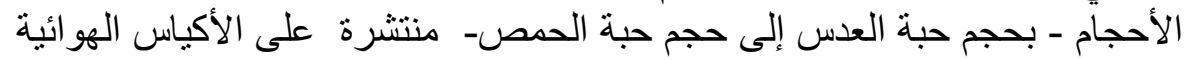
البطنية و الصدرية و الرئتين ، الثكل رقم (1) و الثكل رقم (2).

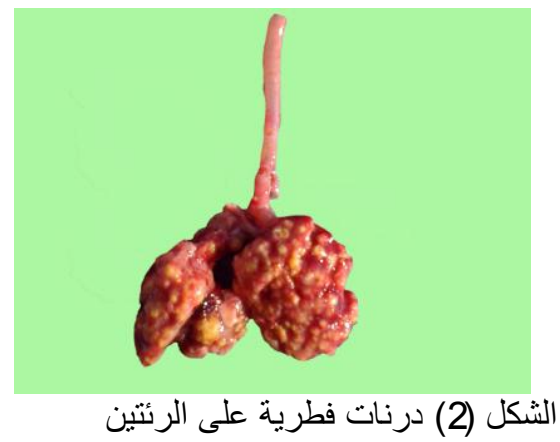

الثكل (2) درنات فطرية على الرئتين

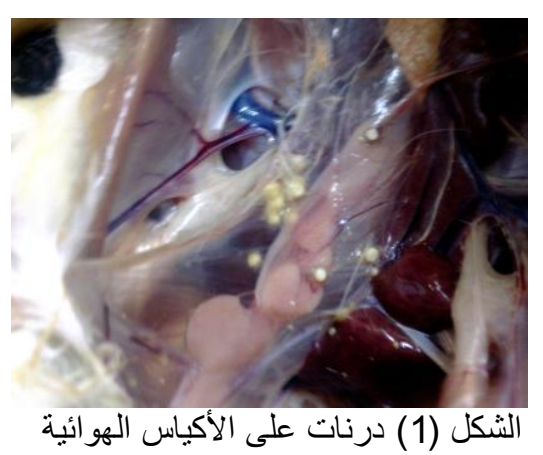

1. العزل والتصنيف

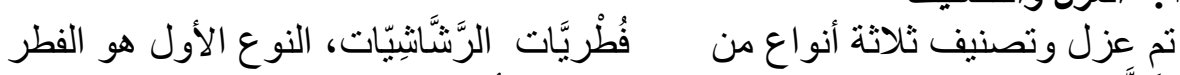

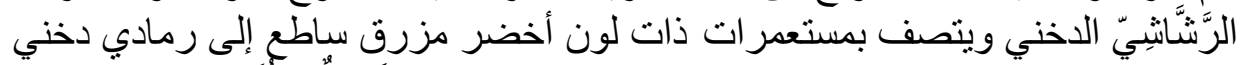

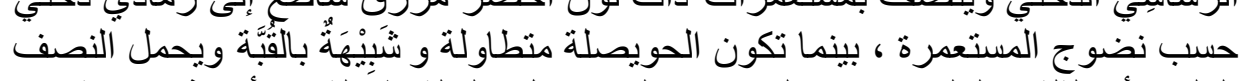

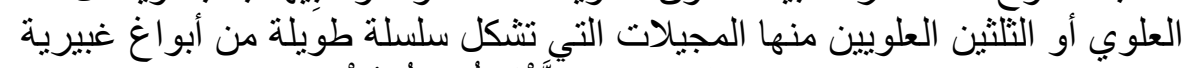

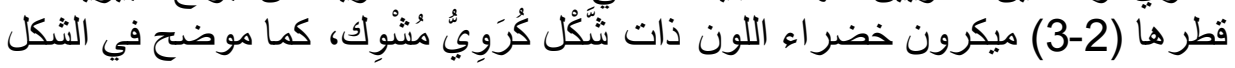




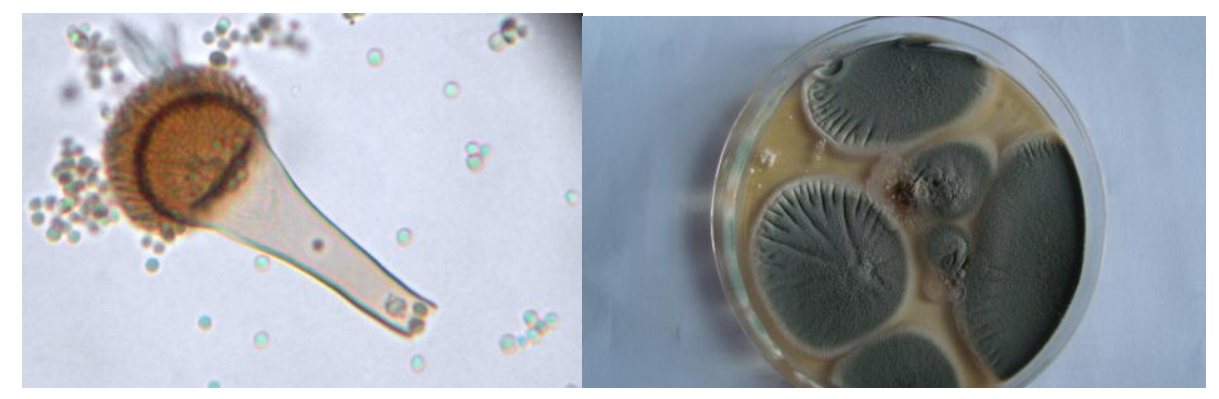

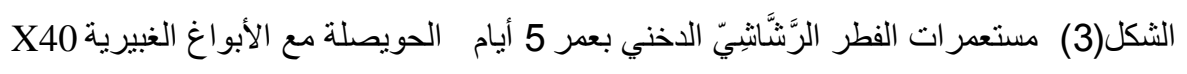

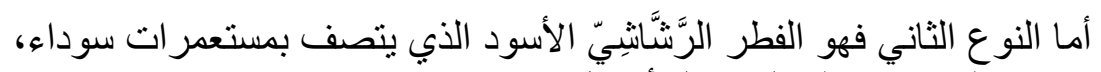

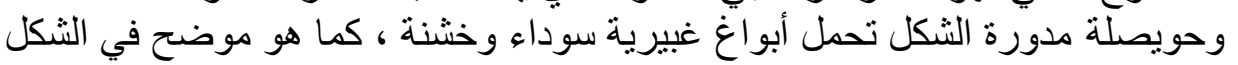

$$
\text { الثنكل(4) مستعمرات الفطر الرَّنَّانِيّيَ الأسود بعمر } 5 \text { أيام الحويصلة مع الأبواغ الغبيرية X10 }
$$

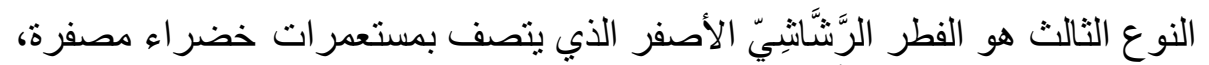

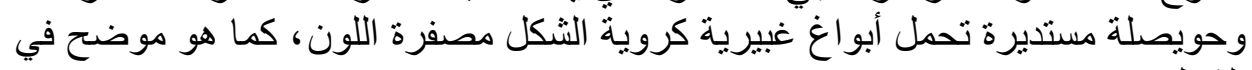

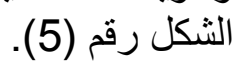

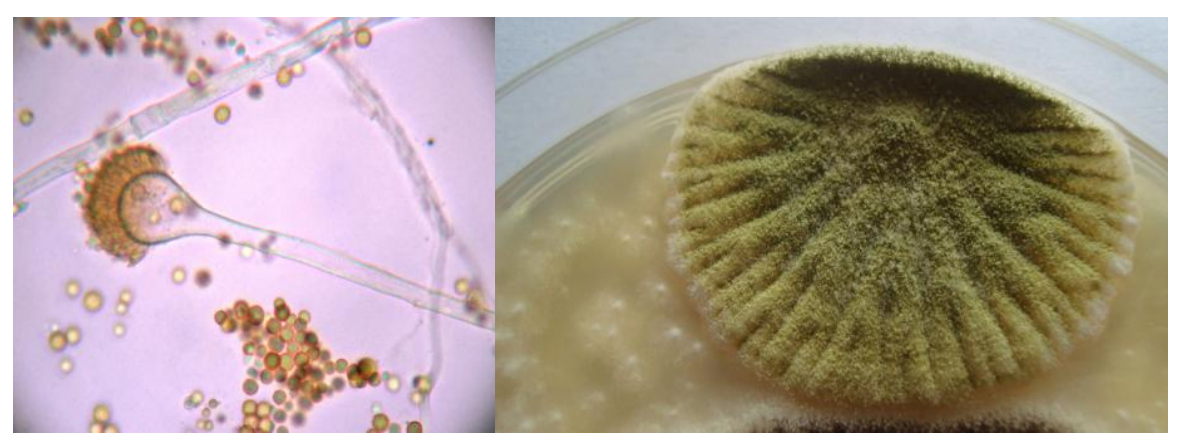

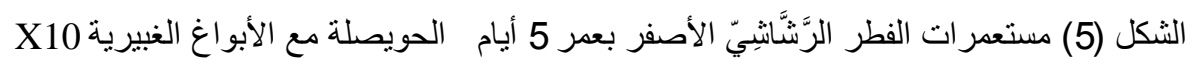

r. معدل العزل لأنواع الرَّثََّّشيّات في مناطق البحث: 


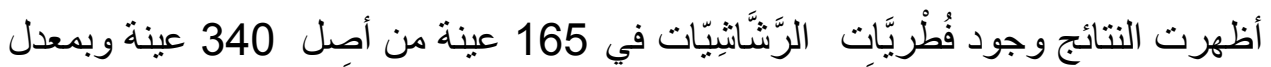

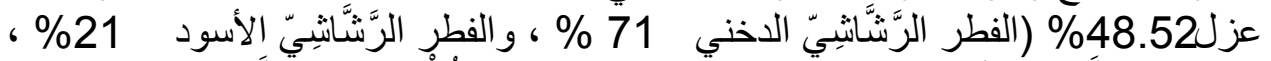

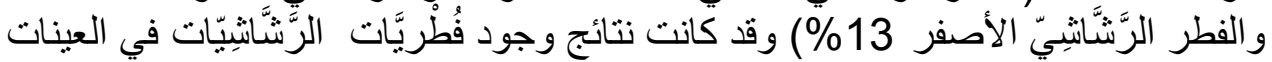

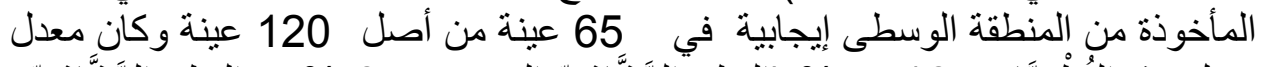

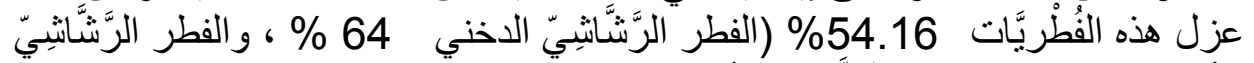

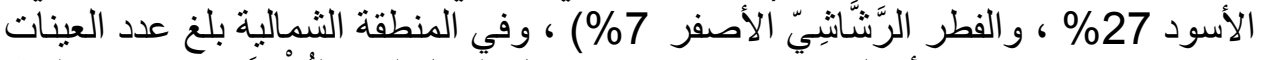

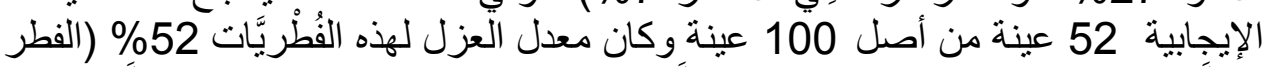
الرَّشَّانثِيّيّ الدخني

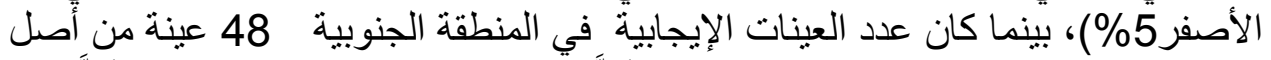

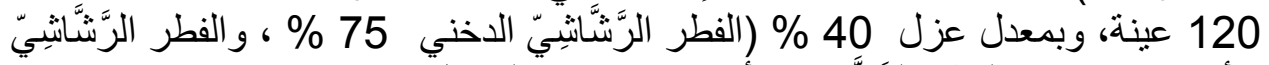

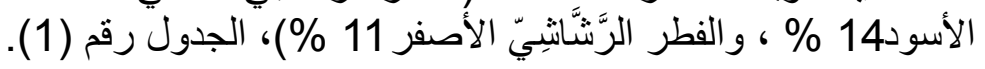

الجدول 1 : معدل العزل لأنواع الرَّشَّانثِيّات في بعض مزارع تربية الفروج في سوريا

\begin{tabular}{|c|c|c|c|c|c|c|}
\hline \multicolumn{3}{|c|}{ تصنيف الأنواع } & \multicolumn{2}{|c|}{ العينات الإيجايية } & \multirow{2}{*}{ الكلي / عدد العددات } & \multirow{2}{*}{ المنطقة } \\
\hline الأصفر & الأسود & الدني & النسبة & العدد & & \\
\hline (\%7.69) 5 & $\mid$ & $\begin{array}{c})^{4} \\
(\% 64.62\end{array}$ & $\% 54.17$ & 65 & $10 / 120$ & الوسطى \\
\hline$(\% 5.77) 3$ & \%17.31) 9 & (\%76.92) 40 & $\% 52$ & 52 & $10 / 100$ & الثمالية \\
\hline$(\% 10.42) 5$ & \%14.58) 7 & ( \% 75) 36 & $\% 40$ & 48 & $10 / 120$ & الجنوبية \\
\hline$(\% 7.88) 13$ & (\%20.61) 34 & $(\% 71.52) 118$ & $\% 48.53$ & 165 & $30 / 340$ & العدد الكلي \\
\hline
\end{tabular}

\section{DISCUSSION}

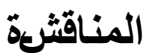

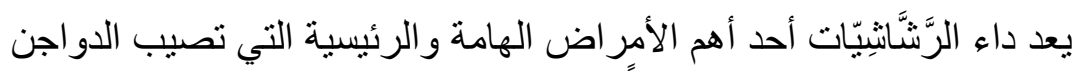

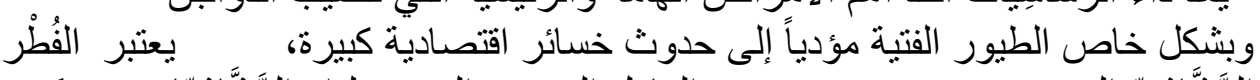

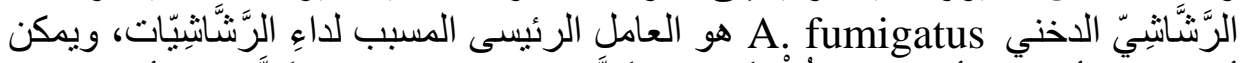

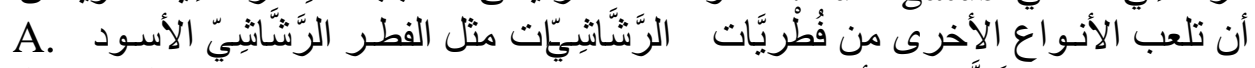

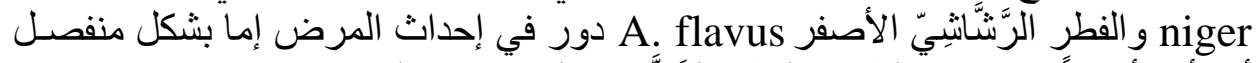

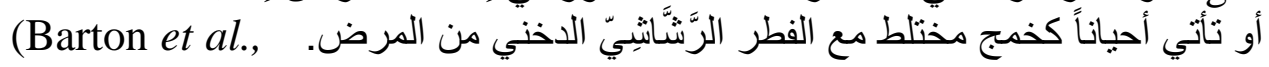
.1992; Joseph 2000; Daly and Kavanagh 2001) 


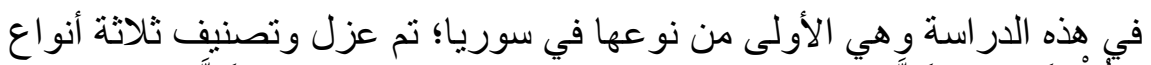

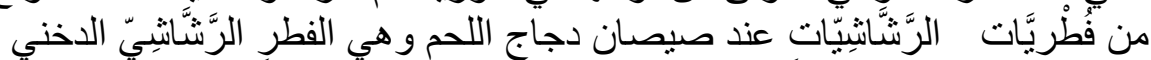

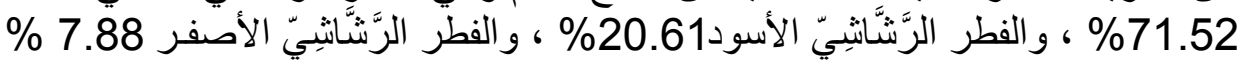

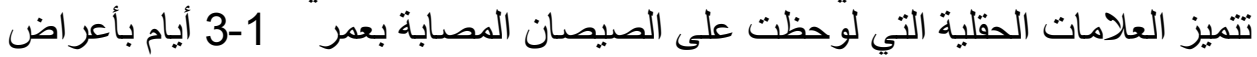

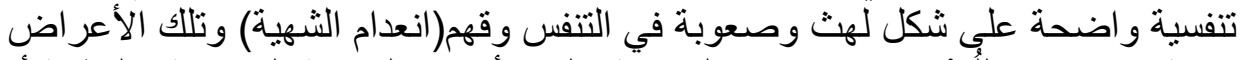

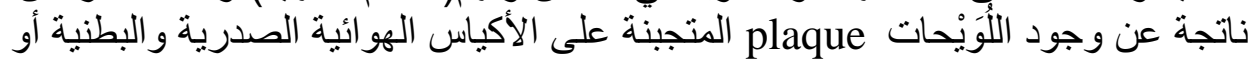

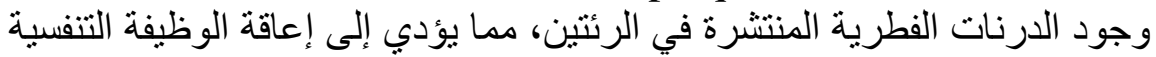

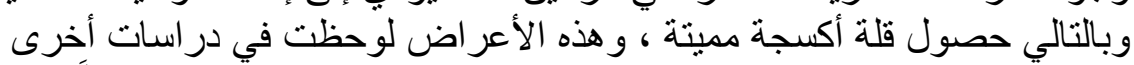

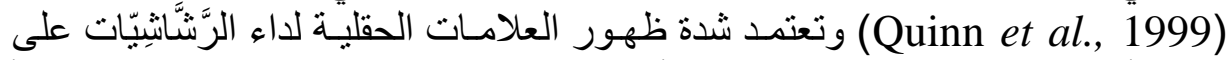

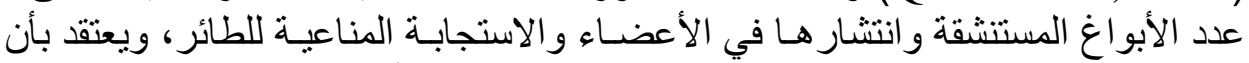

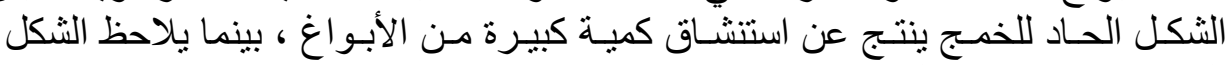

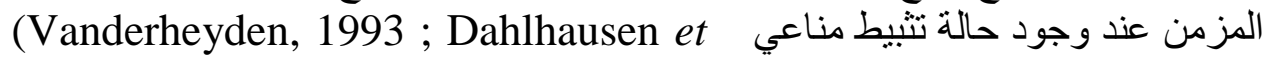
al., 2004)

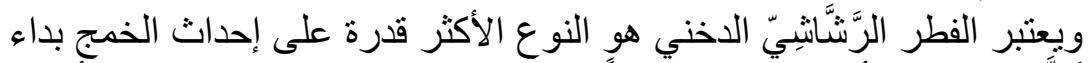

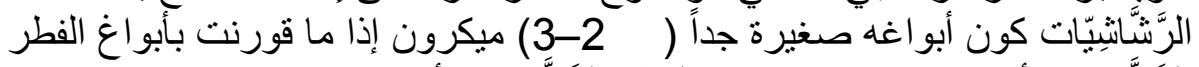

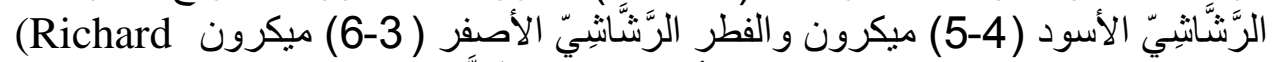

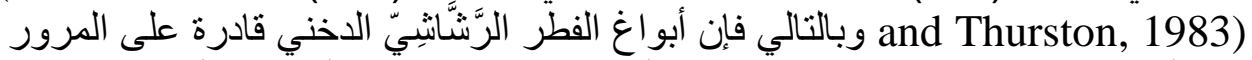

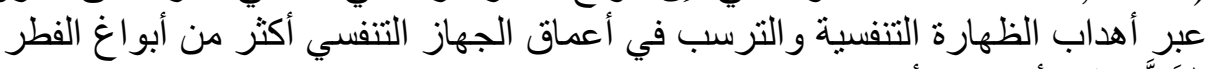
الرَّنَّانثِيّات يعود إلى أسباب عديدة من أهمها؛

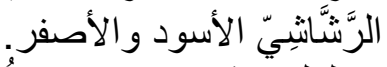

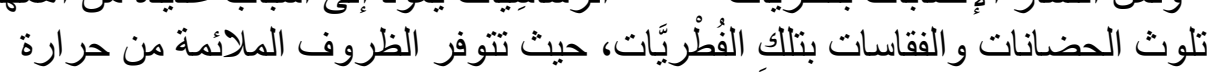

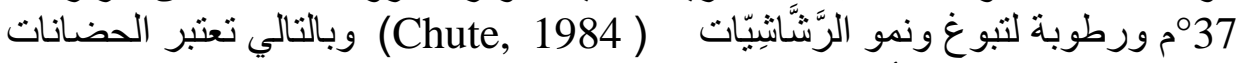

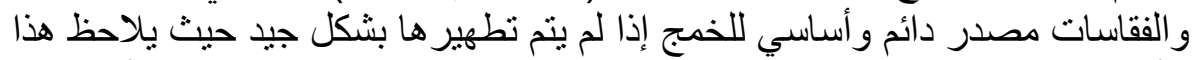

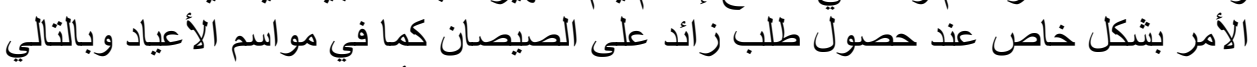

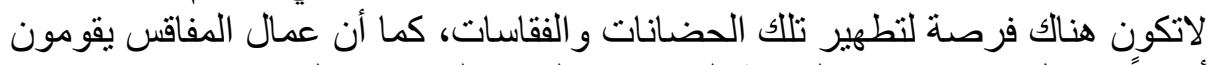

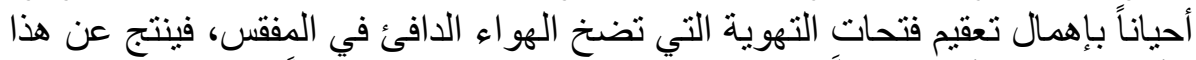

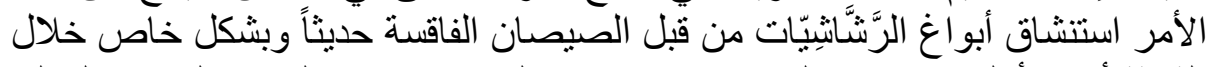

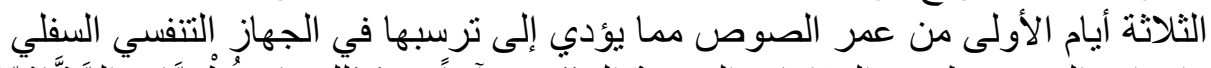

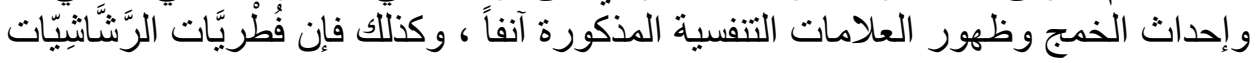

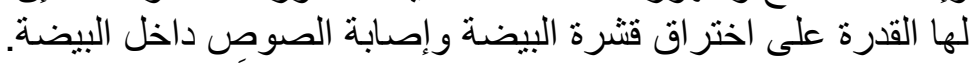

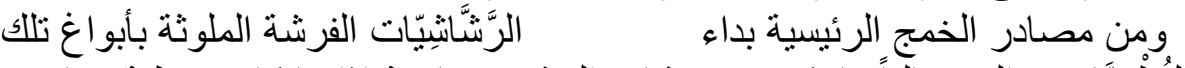

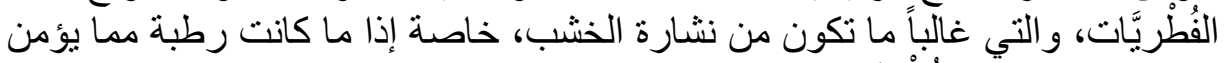

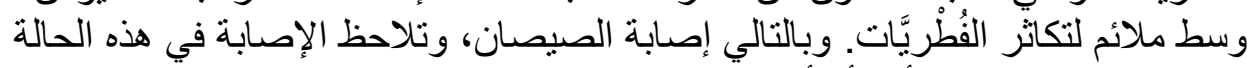

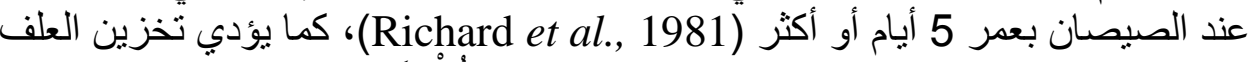

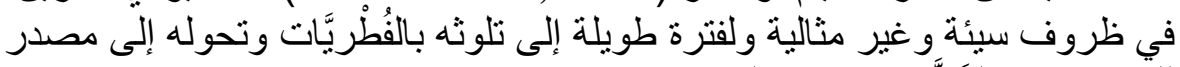

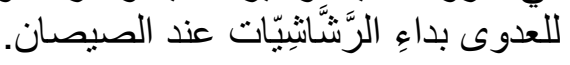




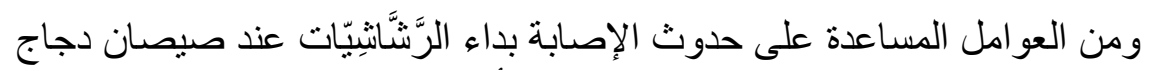

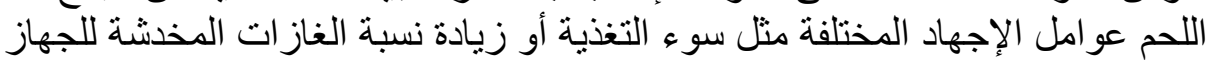

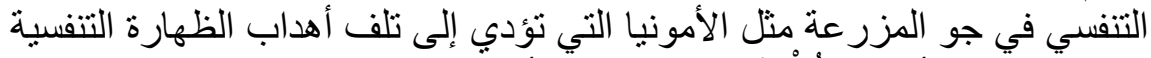

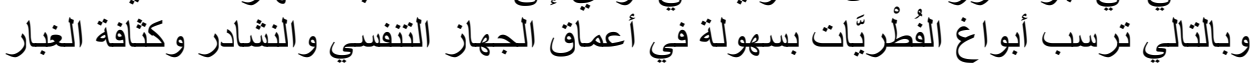

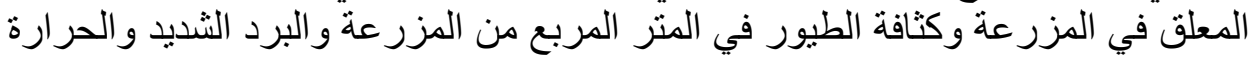

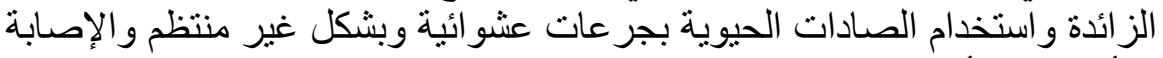
بالأمر اض الأخرى. (Kristensen and Wathes 2000)

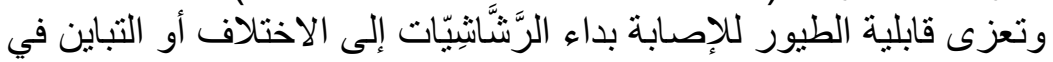

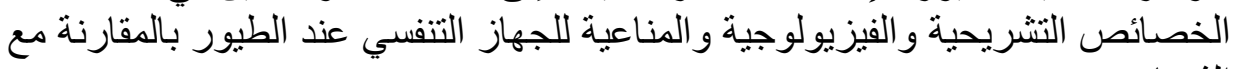
الثنييات.(Toth, 2000 ; Tell, 2005 ; Maina, 2007)

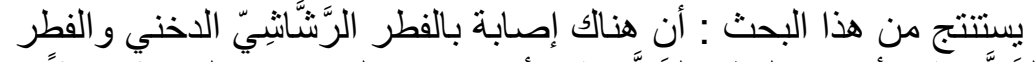

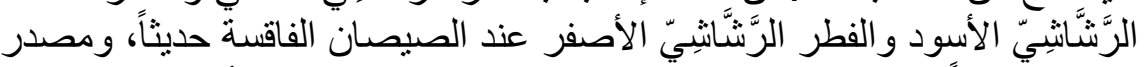

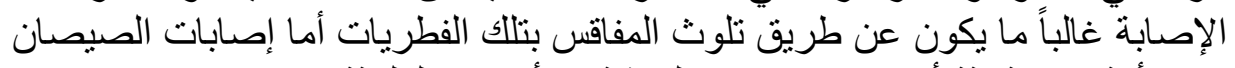

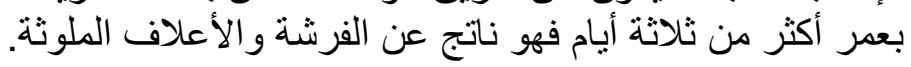

\section{REFERENCES}

Ainsworth, G.C. and Rewell, R.E. (1949): The incidence of aspergillosis in captive wild birds. Journal of Comparative Pathology and Therapeutics 59: 213-224.

Akan, M.; Haziroğlu, R.; Ilhan, Z.; Sareyyüpoğlu, B. and Tunca, R. (2002): A case of aspergillosis in a broiler breeder flock. Avian Dis. 46(2): 497-501.

Austwick, P.K.C. (1968): Mycotic Infections. Symposium of the Zoological Society of London, 24: 249-271.

Barton, J.T.; Daft, B.M.; Read, D.H.; Kinde, H. and Bickford, A.A. (1992): Tracheal aspergillosis in $61 / 2$-week-old chickens caused by Aspergillus flavus. Avian Diseases, 36, 1081_1085.

Beckman, B.J.; Howe, C.W.; Trampel, D.W.; DeBey, M.C.; Richard, J.L. and Niyo, $Y$. (1994): Aspergillus fumigatus keratitis with intraocular invasion in 15-day-old chicks. Avian Dis 38:660-665.

Beernaert, L.A.; Pasmans, F.; Van Waeyenberghe, L.; Haesebrouck, F. and Martel, A. (2010): Aspergillus infections in birds: a review, Avian Pathology. 39(5): 325-331.

Chute, H.L. and O'Meara, D.C. (1958): Experimental fungus infections in chickens. Avian Dis 2:154-166.

Chute, H.L. (1984): Fungal infections. In: Diseases of Poultry, 8th ed.edited by Hofstad. M.S. et al, Iowa State University Press, Ames. Iowa. 
Chute, H.L. and Richard, J.L. (1997): Fungal infections In Diseases of Poultry, 10th Ed.,B.W. Calnek, H.J Barnes, C.W. Beard. L.R. McDo- ugle, and Y.M. Saif (eds.). Iowa State University Press, Ames, IA, U.S.A pp. 351-360.

Dahlhausen, B.; Abbott, R. and VanOverloop, P. (2004): Rapid detection of pathogenic Aspergillus species in avian samples by real-time PCR assay: a preliminary report. In E. Bergman (Ed.). Proceedings of the 25th Annual Conference \& Expo of the Association of Avian Veterinarians (p. 37). New Orleans, LA, USA.

Daly, P. and Kavanagh, K. (2001): Pulmonary aspergillosis: clinical presentation, diagnosis and therapy. Brazilian Journal Biomedical Science; 58: 197.

Joseph, V. (2000): Aspergillosis in raptors. Seminars in Avian and Exotic Pet Medicine, 9: 66-74.

Kathryn A. Converse (2007): Aspergillosis IN: Infectious Diseases of Wild Birds. Blackwell Publishing Professional. 2121 State Avenue, Ames, Iowa 50014, USA.

Kristensen, HH. and Wathes, CM. (2000): Ammonia and poultry welfare: a review. World.s Poultry Science Journal; 56(3): 235-245.

Kunkle, R.A. (2003): Aspergillosis, In: Diseases of Poultry, Saif, Y.M., Barnes, H. J., Glisson, J. R., Fadly, A. M., Mcdougald, L. R., and Swayne, D.E. (eds), 11th Ed., Iowa State University Press: Ames. pp: 883-895.

Kunkle, R.A. and Rimler, R.B. (1996): Pathology of acute aspergillosis in turkeys. Avian Dis 40: 875-886.

Maina, J.N. (2002): Some recent advances on the study an unders- tanding of the functional design of the avian lung: morphological and morphometric perspectives. Biological Reviews of the Cambridge Philosophical Society, 77: 97-152.

Martin, M.P.; Bouck, K.P.; Helm, J.; Dykstra, M.J.; Wages, D.P. and Barnes, H.J. (2007): Disseminated Aspergillus flavus infection in broiler breeder pullets. Avian Dis. 51(2): 626-31.

O'Meara, D.C. and Chute, H.L. (1959): Aspergillosis experimentally produced in hatching chicks. Avian Dis 3: 404-406.

Olsen, G.H.; Nicolich, J.M. and Hoffman, D.J. (1990): Areview of some causes of death in avian embryos. In Proceedings of the Association of Avian Veterinarians, Phoenix, AZ,U.S.A., pp. 106-111.

Qinn, P.J.; Carter, M.E.; Markey, B. and Carter, G.R. (1999): Clincal veterinary microbiology. Mosby, 3th ed, PP: 391-394. 
Richard, J.L.; Cutlip, R.C.; Thurston, J.R. and Songer, J. (1981): Response of turkey poults to aerosolized spores of Aspergillus fumigatus and aflatoxigenic and nonaflatoxigenic strains of Aspergillus flavus. Avian Dis 25: 53-67.

Richard, J.L. and Thurston, J.R. (1983): Rapid hematogenous dissemination of Aspergillus fumigatus and A. flavus spores in turkey poults following aerosol exposure. Avian Diseases, 27: 1025-1033.

Schneemann and Schaffner (1999): Host defense mechanism in Aspergillus fumigatus infections. In Aspergillus fumigatus, Biology, Clinical Aspects and Molecular Approaches to Pathogenicity, A.A.A. Brakhage, J.B. Schmidt, and A. Jahn (eds.). Karger, New York, NY, U.S.A., pp. 57-68.

Tell, L.A. (2005): Aspergillosis in mammals and birds: impact on veterinary medicine. Medical Mycology Supplement, 1, S7-S73.

Toth, T.E. (2000): Nonspecific cellular defense of the avian respiratory system: a review. Developmental and Comparative Immunology, 24: 121-139.

Vanderheyden, N. (1993): Aspergillosis in psittacine chicks. In G. Jackson (Ed.). Proceedings of the Annual Conference of the Association of Avian Veterinarians (p. 207). Nashville, TN, USA.

Veen, P.J. (1973): Torticollis and disease of the respiratory tract, caused by Aspergillus fumigatus in fowl. Netherlands J. Vet. Sci. 5: 132-133. 